\title{
Chronic groin pain in an amateur soccer player
}

\author{
C Cetin, U Sekir, Y Yildiz, T Aydin, F Ors, T A Kalyon
}

Br J Sports Med 2004;38:223-224. doi: 10.1136/bjsm.2002.003483

Chronic groin pain is common in soccer players because of the biomechanics of kicking causing recurrent stress to the abdominal muscles, groin flexors, and adductor muscles. Myositis ossificans in adductor muscles is a rare cause of chronic groin pain in soccer players. Only two cases have been reported and the iliopsoas muscle was involved in both. This case report emphasises the importance of direct radiography for diagnosis in chronic groin pain and is a reminder that the development of myositis ossificans in the adductor muscles may be a cause.

$M$ yositis ossificans is heterotopic bone localised in the soft tissues adjacent to bone and is associated with trauma, surgery, or disease such as paraplegia. It is a common complication of a combination of contusion with haematoma formation involving muscle. The importance of this condition rests in the fact that contusions are usually viewed as minor injuries by coaches and athletes and thus are not treated with much concern, although appropriate management of this initial injury can prevent or lessen its development. ${ }^{1}$

The most common cause of myositis is trauma, and it occurs primarily in contact sports such as football, rugby, and lacrosse. ${ }^{2}$ There are several risk factors that should be avoided: continuing to play after injury, early massage of the injured area, and application of heat to the area. Other predisposing factors may be passive, forceful stretching, too rapid progression of rehabilitation, premature return to activity, reinjury of the same area, and innate predisposition to ectopic bone formation. The quadriceps, femoris, and biceps brachii are most often involved, reflecting their exposure to direct trauma. Roentgenographic signs of injury are present in the third to sixth week after injury. The initial appearance is that of fluffy calcification with indistinct margins lying in the soft tissue. ${ }^{3}$

In soccer players, the incidence of groin, pelvic, and hip injury has been reported in various European studies ranging from $0.5 \%$ to $28 \%{ }^{4}$ Martens et al ${ }^{5}$ treated 109 athletes with either adductor tendinitis and/or rectus abdominus tendopathy; of these, 95 (87\%) were soccer players.

Chronic groin pain, or pubalgia, is often encountered in soccer players and is probably caused by the biomechanics of forceful kicking in which abdominal muscles and hip flexors and adductors are repetitively stressed. Strains of these musculotendon structures are commonly the cause. Other possible sources of groin pain, such as stress fractures of the femoral neck or pubic ramus, avulsion fractures, inguinal hernias, osteitis pubis, prostatitis, Legg-Calvé-Perthes disease, acetabular labral tears, and iliopectineal bursitis, should first be ruled out. ${ }^{67}$

\section{CASE REPORT}

The case is reported of a 29 year old man who had been an amateur soccer player for 14 years. In a competition two years previously, he felt a sharp groin pain with an audible popping after extending his left leg to the ball; this was due to eccentric loading. He did not continue to play because he could not weight bear on his left leg. Ice treatment was not administered during the first few days, but, after massage, intramuscular diclofenac preparation was applied. The patient rested from sport for four weeks after the acute injury, and then restarted training with the team. He received no other physiotherapy for two years. He occasionally complained of pain in the groin region during sporting activities over those two years and was finally admitted to our clinic.

\section{Physical examination}

No diagnostic findings were obtained. However, we established, on palpation at the adductor muscle insertion area, tenderness and a palpable mass. Although the patient had full range of motion in all directions of the left hip, he felt pain at the end range of abduction. Stretching to abduction and resistive adduction tests were painful.

\section{Diagnostic procedures}

A pelvic radiogram (fig 1) showed mature bone fragments in the foramen obturatorium. Magnetic resonance imaging (MRI) scans (figs 2 and 3) showed these bone fragments to have a cortex and medulla, and were close to the pubic ramus and within the soft tissue. Computed tomography showed that this formation was not connected to the pubic ramus but was intramuscular (the adductor brevis muscle) (fig 4).

Isokinetic measurements of the adductor muscles of the involved hip joint at $120 \%$ angular speed at the baseline examination detected a deficit of $49 \%$ compared with the contralateral side. This deficit had decreased to $15 \%$ after three months of treatment (Cybex NORM Isokinetic Test Device, Blue Sky Software Corp, New York, USA). In addition, the athlete was able to do sport specific activities such as running figure of eights, shuttle runs, cariocas, and kicking without any symptoms.

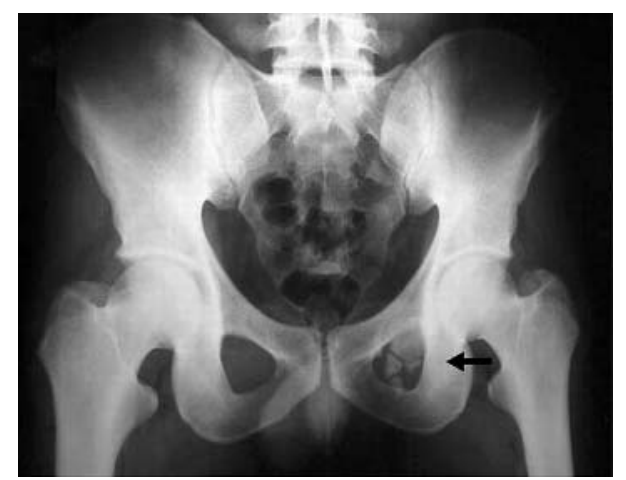

Figure 1 Pelvic radiogram showing mature bone fragments in the foramen obturatorium. 


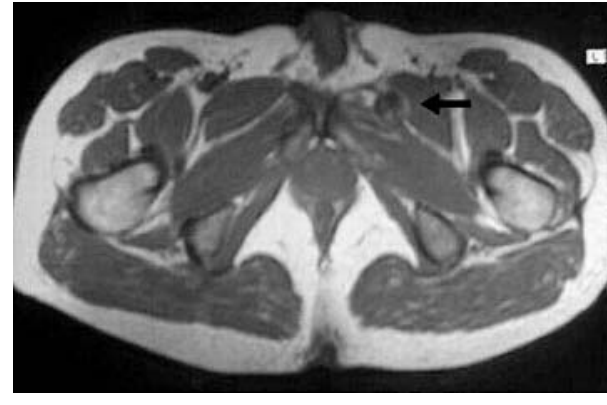

Figure 2 T1 weighted axial magnetic resonance image showing myositis ossificans in the left adductor brevis, adjucent but not connected to the public ramus (black arrow).

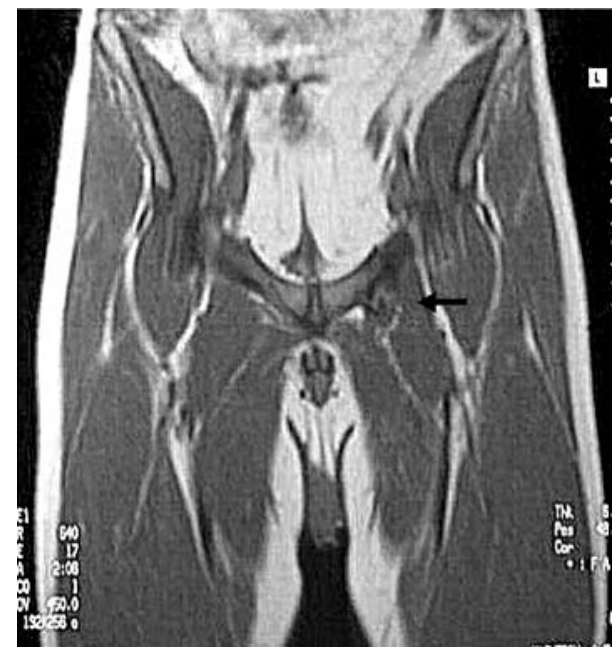

Figure $3 \mathrm{Tl}$ weighted coronal magnetic resonance image showing that bone fragments have a cortex and medullae, close to the pubic ramus and within the soft tissue. This lesion looks like bone fragmentation, but there is no fracture or cortical defect in the pubic ramus.

\section{DISCUSSION}

Myositis ossificans, particularly in its early and intermediate phases, displays MRI characteristics that are often equated with malignancy. ${ }^{8}$ The formation, observed with imaging techniques in this case, was interpreted as an ossification in the adductor brevis muscle rather than osteosarcoma on the basis of the history of the injury and because of the radiodense mature bone at the periphery of the lesion with a more lucent centre and because it was not associated with bone structures. This is different from tumours, which tend to develop more dense calcification centrally. ${ }^{3}$

We did not consider this to be an avulsion fracture because both of the pubic ramus were symmetrical on MRI and computed tomography scans, their borders were smooth, and the density defined was localised in the muscle.

We prescribed non-steroidal anti-inflammatory drugs, ice application, stretching, and strength exercises for the adductor muscles. However, in rare cases, surgical removal of a symptomatic lesion is indicated for persistent pain, usually no sooner than a year after onset. ${ }^{3}$

Myositis ossificans in adductor muscles is a rare cause of chronic groin pain in soccer players. No cases of myositis ossificans in adductor muscles of athletes have previously been reported, but there have been two cases $^{910}$ in the iliopsoas muscle.

\section{Take home message}

Myositis ossificans in the adductor muscles is a rare cause of chronic groin pain in soccer players. No other cases have been reported, but two cases have been reported in the iliopsoas muscle.

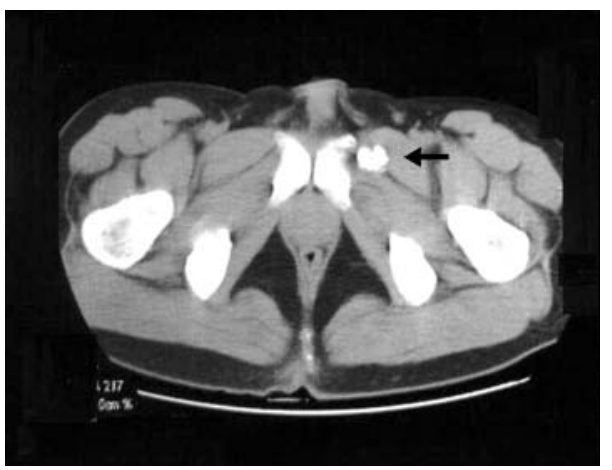

Figure 4 Computed tomography scan showing that the bone fragments were not connected to the pubic ramus but have an intramuscular (adductor brevis) localisation.

This case report emphasises the importance of using direct radiography in the diagnosis of chronic groin pain in athletes and is reminder that the development of myositis ossificans in adductor muscles can be a cause.

\section{Authors' affiliations}

C Cetin, Department of Sports Medicine, Medical Faculty of Süleyman Demirel University, Isparta, Turkey

U Sekir, Department of Sports Medicine, Medical Faculty of Uludag

University, Bursa, Turkey

T Aydin, T A Kalyon, Department of Sports Medicine, Gulhane Military Medicine Faculty, Ankara, Turkey

Y Yildiz, Gulhane Askeri Tip Akademisi, Ankara

F Ors, Department of Radiodiagnostics, Gulhane Military Medicine Faculty

Correspondence to: Dr Cetin, Department of Sports Medicine, Medical Faculty of Süleyman Demirel University, 32260 Isparta, Turkey; cetin@medicine.ankara.edu.tr

Accepted 11 March 2003

\section{REFERENCES}

1 Zachazewski EJ, Magee DJ, Quillen WS. Athletic injuries and rehabilitation. Philadelphia: WB Saunders Company, 1996:613-14.

2 Thorndike A. Myositis ossificans traumatica. J Bone Joint Surg 1940;22:315-23.

3 Fu FH, Stone DA. Sports injuries; mechanisms, prevention, treatment. Philadelphia: Williams\&Wilkins, 1994:758-9.

4 Smodlaka V. Groin pain in soccer players. Phys Sportsmed 1980;8:57-61.

5 Martens MA, Hansen L, Mulier JC. Adductor tendinitis and musculus abdominis tendinopathy. Am J Sports Med 1987;15:353-6.

6 Ekberg O, Persson NH, Abrahamsson PA, et al. Longstanding groin pain in athletes: a multidisciplinary approach. Sports Med 1998;6:56-61.

7 Renström PA. Tendon and muscle injuries in the groin area. Clin Sports Med 1992;11:815-31.

8 Kransdorf MJ, Meis JM, Jelinek JS. Myositis ossificans: MR appearance with radiologic-pathologic correlation. AJR Am J Roentgenol 1991;157:1243-8.

9 Petropoulos AS, Sferopoulos NK. Post traumatic myositis ossificans of the iliopsoas muscle. Apropos of a case with review of the literature. Rev Chir Orthop Reparatrice Appar Mot 1997;83:747-51.

10 Thorseth K. A case of traumatic myositis ossificans in the iliopsoas muscle. Acta Orthop Scand 1968;39:73-5. 